\title{
Absorção de P, Mg, Ca e K e tolerância de genótipos de arroz submetidos a estresse por alumínio em sistemas hidropônicos
}

\author{
Nutrient absorption in aluminum stressed rice plants under hydroponic culture
}

\author{
Fábio Almeida de Freitas ${ }^{1}$ Mauricio Marini Kopp ${ }^{1}$ Rogério Oliveira de Sousa ${ }^{2}$ Paulo Dejalma Zimmer $^{1}$ \\ Fernando Irajá Félix de Carvalho ${ }^{1}$ Antonio Costa de Oliveira ${ }^{3}$
}

\section{RESUMO}

Solos com concentrações elevadas de alumínio $\left(A l^{3+}\right)$, podem prejudicar o desenvolvimento e a absorção de nutrientes de plantas de arroz. $O$ objetivo do experimento foi avaliar o desempenho de dezoito genótipos de arroz quanto a absorção de $\mathrm{P}, \mathrm{Mg}$, Ca e $\mathrm{K}$ e identificar genótipos com bom desempenho quando submetidos ao estresse por $\mathrm{Al}^{3+}$ em sistema hidropônico. Foram utilizados quatro níveis de $A l^{3+}(0,10,20$ e $30 \mathrm{mg} \mathrm{L}^{-1}$ ) e o delineamento experimental foi blocos casualizados com três repetições. As plântulas permaneceram em sistema hidropônico por 20 dias sob efeito dos tratamentos, e após foram avaliadas quanto ao comprimento de raízes (CR) e teores de P, $\mathrm{Mg}$, Ca e K. Todas as variáveis apresentaram reduções significativas nos seus valores, e os genótipos apresentaram diferentes desempenhos na absorção de nutrientes frente aos tratamentos, com exceção do nutriente Mg que apresentou mesma resposta para todos os genótipos avaliados. Baseado na variável CR, os genótipos Felune e Taim foram considerados como mais tolerante e sensivel ao $A l^{3+}$, respectivamente. Para absorção de nutrientes, os genótipos apresentaram comportamentos muito diferenciais para cada elemento avaliado, sendo que também o genótipo Felune obteve elevados índices de absorção. Todas as variáveis revelaram correlações significativas entre si.

Palavras-chave: Oryza sativa, alumínio tóxico, variabilidade.

\section{ABSTRACT}

Soils with high aluminum $\left(A l^{3+}\right)$ concentrations can affect the development and nutrient absorption of rice plants. The goals of this study were to evaluate the absorption of $P, M g, C a$ and $K$ in 18 rice genotypes and their overall performance when subjected to $\mathrm{Al}^{3+}$ stress in hydroponic systems. The experimental design was randomized blocks with 3 replications and four Al $l^{3+}$ levels $\left(0,10,20\right.$ and $\left.30 \mathrm{mg} \mathrm{L}^{-1}\right)$.
Plantlets were treated for 20 days and evaluated for root length $(\mathrm{CR})$ and $\mathrm{P}, \mathrm{Mg}, \mathrm{Ca}$ and $\mathrm{K}$ contents. All variables presented significant reductions in their values, and the genotypes presented different performance in nutrient absorption when facing different treatments, with an exception for $\mathrm{Mg}$ absorption response in which all genotypes evaluated were similar. Based on the variable $C R$, the genotypes Felune and Taim were considered the most tolerant and sensitive to $A l^{3+}$, respectively. Regarding nutrient absorption, the genotypes presented variable responses to each evaluated nutrient, nevertheless the genotype Felune presented also high absorption levels. All the variables presented significant correlations to each other.

Key words: Oryza sativa, toxic aluminum, variability.

\section{INTRODUÇÃO}

A toxicidade ao alumínio é um dos principais limitantes da expansão da produtividade em solos ácidos, os quais representam uma grande área com capacidade produtiva de regiões tropicais e subtropicais (UEXKULL \& MUTERT, 1995). Sabe-se que a ocorrência de toxidez por alumínio $\left(\mathrm{Al}^{3+}\right)$ é bastante representativa nos solos brasileiros, que além de altos índices de acidez, apresentam baixos teores de P, Ca e Mg (OLMOS \& CAMARGO, 1976).

A obtenção de cultivares tolerantes à toxicidade de alumínio vem despertando o interesse de muitas áreas da pesquisa agrícola, particularmente quando se pretende explorar eficientemente solos com acidez subsuperficial e elevado nível de alumínio, de difícil correção com manejo químico. Níveis elevados

${ }^{1}$ Departamento de Fitotecnia, Faculdade de Agronomia Eliseu Maciel (FAEM), Universidade Federal de Pelotas (UFPel). Pelotas, RS, Brasil.

${ }^{2}$ Departamento de Solos, FAEM, UFPel. Pelotas, RS, Brasil.

${ }^{3}$ Departamento de Fitotecnia, FAEM, UFPel. Universidade Federal de Pelotas, Faculdade de Agronomia Eliseu Maciel, Campus Universitário S/N, Caixa Postal-354, CEP: 96001-970, Pelotas, Rio Grande do Sul, Brasil. Autor para correspondência. 
de alumínio associados a períodos de deficiência hídrica reduzem drasticamente a produtividade, inviabilizando, às vezes, o cultivo em área de solos ácidos (SAWAZAKI \& FURLANI, 1987). A calagem corrige apenas as camadas superficiais do solo e o subsolo permanece ainda ácido, podendo restringir o crescimento das raízes das cultivares sensíveis ao alumínio. Desta forma, as plantas assumem maior suscetibilidade à seca, por serem impedidas de obter água das camadas mais profundas do solo, o que afeta significativamente a produção de grãos (FOY et al., 1965; CAMARGO et al., 1998). Além disso, o alumínio interfere na absorção e movimentação do fósforo, cálcio, magnésio e molibdênio (OLMOS et al., 1976). Sob o estresse desse elemento, as plantas paralisam seu crescimento radicular, reduzem a absorção de nutrientes, refletindo num declínio na produção (BRONDANI \& PAIVA, 1996). HOWELER \& CADAVID (1976) verificaram que as plantas tolerantes ao alumínio apresentavam teores de fósforo, cálcio, magnésio e potássio mais altos que as plantas sensíveis.

Vários mecanismos de tolerância ao alumínio vem sendo postulados (KOCHIAN, 1995), e podem ser classificados, segundo JO et al. (1997), em dois grupos: i) mecanismos externos, em que as plantas tolerantes liberam ácidos orgânicos pela raiz, geralmente citrato e malato, que se ligam ao alumínio formando complexos estáveis impedindo a absorção pela planta (PELLET et al., 1995; RYAN et al., 1995); ii) mecanismos internos, em que o alumínio é absorvido para o interior da planta e conseqüentemente para a célula, onde é inativado por alguma enzima ou isolado no interior do vacúolo. Os mecanismos de tolerância ao alumínio em arroz ainda são desconhecidos, porém FAGERIA \& ZIMMERMANN (1979) e FERREIRA et al. (1995) relataram variabilidade para o caráter.

Uma forma adequada de avaliação de genótipos para tolerância ao $\mathrm{Al}^{3+}$ pode ser realizada em sistemas eficientes de hidroponia sob condições controladas (CAMARGO, 1981). Enquanto a avaliação de genótipos em ambientes artificiais não leva em consideração as reais pressões do ambiente (DUNCAN \& BALIGAR, 1990), a seleção em ensaios de campo reúne grande número de variáveis não controladas, tais como tolerâncias diferenciais a estresses climáticos, bióticos ou nutricionais (WRIGHT, 1989). Entretanto, CAMARGO \& OLIVEIRA (1981) mostraram uma elevada correlação entre a tolerância de cultivares de trigo a diferentes níveis de alumínio em solução nutritiva e no solo. $\mathrm{O}$ objetivo do presente trabalho foi avaliar a tolerância ao alumínio e a interferência deste elemento sobre a absorção de nutrientes em 18 genótipos de arroz em solução hidropônica.

\section{MATERIAL E MÉTODOS}

O experimento foi conduzido no Laboratório de Hidroponia do Centro de Genômica e Fitomelhoramento (CGF) e no Departamento de Solos da Faculdade de Agronomia Eliseu Maciel (FAEM) da Universidade Federal de Pelotas (UFPel). Os 18 genótipos de arroz utilizados fazem parte da coleção de trabalho do banco de germoplasma do CGF/FAEM/ UFPel e suas descrições segundo sistema de cultivo são apresentadas na tabela 1. As sementes foram colocadas para germinar em papel germinador enrolado, mantido de pé na câmara germinadora a uma temperatura de $25^{\circ} \mathrm{C}$, durante 48 horas. Na seqüência, as plântulas foram transferidas para telas de nylon adaptadas a tampas de potes de $5,5 \mathrm{~L}$ que continham solução nutritiva adicionada dos tratamentos. Os potes foram colocados no sistema hidropônico em banhomaria $\left(25^{ \pm} 1^{\circ} \mathrm{C}\right)$, com iluminação artificial controlada. $\mathrm{O}$ delineamento experimental utilizado foi de blocos casualizados com parcelas subdivididas, com doses de alumínio na parcela e genótipos de arroz na subparcela e três repetições, sendo que cada repetição foi constituída de três plântulas. A solução nutritiva utilizada foi descrita por CAMARGO \& OLIVEIRA, 1981 e é composta por: Nitrato de cálcio - $\mathrm{Ca}\left(\mathrm{NO}_{3}\right)_{2} 4$ $\mathrm{mM}$, Sulfato de magnésio - $\mathrm{MgSO}_{4} 2 \mathrm{mM}$, Nitrato de potássio - $\mathrm{KNO}_{3} 4 \mathrm{mM}$, Sulfato de amônio - $(\mathrm{NH} 4)_{2} \mathrm{SO}_{4}$ 0,435mM, Potássio fosfato - $\mathrm{KH}_{2} \mathrm{PO}_{4} 0,5 \mathrm{mM}$, Ácido bórico $-\mathrm{H}_{3} \mathrm{BOI}_{3} 10 \mu \mathrm{M}$, Molibdato de sódio - $\mathrm{NaMoO}_{4}$ $0,10 \mu \mathrm{M}$, Cloreto de sódio - $\mathrm{NaCl} 30 \mu \mathrm{M}$, Sulfato de zinco - $\mathrm{ZnSO}_{4} 0,8 \mu \mathrm{M}$, Sulfato de cobre - $\mathrm{CuSO}_{4} 0,3 \mu \mathrm{M}$, Sulfato de manganês - $\mathrm{MnSO}_{4} 2 \mathrm{mM}$. Foram utilizados quatro níveis de alumínio: 0, 10, 20 e 30 $\mathrm{mg} \mathrm{L}^{-1}$, adicionados como $\mathrm{Al}_{2}\left(\mathrm{SO}_{4}\right)_{3} 18 \mathrm{H}_{2} \mathrm{O}$. O Fe - EDTA, foi substituído por $\mathrm{FeCl}_{3}$ para evitar uma possível precipitação do $\mathrm{Al}^{3+}$. $\mathrm{O}$ pH das soluções foi verificado diariamente e, se necessário, corrigido para uma faixa de 4,2 a 4,6 utilizando $\mathrm{NaOH}$ ou $\mathrm{H}_{2} \mathrm{SO}_{4}(1 \mathrm{M})$. As soluções foram renovadas a cada quatro dias para manter as concentrações de nutrientes e de alumínio próximas dos valores preestabelecidos.

Após 20 dias em solução nutritiva adicionada dos tratamentos o experimento foi concluído e as plantas foram retiradas do sistema hidropônico para as seguintes avaliações: comprimento máximo do sistema radicular (CR), matéria seca da parte aérea (MSPA), e concentrações de fósforo (P), magnésio $(\mathrm{Mg})$, cálcio $(\mathrm{Ca})$ e potássio $(\mathrm{K})$ na MSPA, segundo metodologias descritas por TEDESCO et al. (1995).

Para classificação dos níveis de tolerância, calculou-se para cada concentração de alumínio (10, 20 e 30 $\mathrm{m} \mathrm{L} \mathrm{L}^{-1}$ ), o índice de tolerância relativa (ITR) 
Tabela 1 - Índices de tolerância relativa (ITR) obtido a partir da média de três repetições do comprimento das raízes dos 18 genótipos de arroz medidos após a permanência nas soluções tratamento com doses crescentes de alumínio.

\begin{tabular}{|c|c|c|c|c|c|c|c|}
\hline \multirow{3}{*}{$\begin{array}{l}\text { Genótipos } \\
\text { 1- Taim }\end{array}$} & \multirow{3}{*}{$\begin{array}{c}\text { Sistema de cultivo* } \\
\text { Irrigado }\end{array}$} & \multicolumn{6}{|c|}{ Níveis de alumínio $\left(\mathrm{mg} \mathrm{L}^{-1}\right)$} \\
\hline & & \multicolumn{2}{|c|}{10} & \multicolumn{2}{|c|}{20} & \multicolumn{2}{|c|}{30} \\
\hline & & $-0,5$ & S & $-0,6$ & $S$ & 0,7 & $\mathrm{~S}$ \\
\hline 2- L 144 & Irrigado & 7,0 & $\mathrm{~T}$ & 0,7 & $\mathrm{~S}$ & 2,1 & MS \\
\hline 3- Chui & Irrigado & 3,0 & MT & 1,5 & MS & 0,7 & S \\
\hline 4- $2 / 52 / 4$ & Sequeiro & 5,0 & $\mathrm{~T}$ & 5,0 & $\mathrm{~T}$ & 5,0 & $\mathrm{~T}$ \\
\hline 5- BR IRGA 417 & Irrigado & 8,0 & $\mathrm{~T}$ & 2,1 & MS & 1,0 & $\mathrm{~S}$ \\
\hline 6- Felune & Sequeiro & 4,5 & $\mathrm{~T}$ & 5,8 & $\mathrm{~T}$ & 4,7 & $\mathrm{~T}$ \\
\hline 7- BR IRGA 410 & Irrigado & 1,0 & $\mathrm{~S}$ & 1,0 & S & 1,0 & $S$ \\
\hline 8- Epagri 111 & Irrigado & 3,5 & MT & 1,8 & MS & $-0,1$ & S \\
\hline 9- Supremo 1 & Irrigado & $-0,5$ & S & 1,3 & MS & 0,2 & $\mathrm{~S}$ \\
\hline 10- Zebú Branco & Sequeiro & $-1,0$ & S & 0,2 & S & 1,1 & MS \\
\hline 11- Matsuyama & Sequeiro & 0,5 & S & 0,9 & S & 2,6 & MS \\
\hline 12- IAC 1246 & Sequeiro & 2,5 & MS & 3,3 & MT & 3,7 & MT \\
\hline 13- Toukyo H. & Sequeiro & 2,5 & MS & 1,3 & MS & 0,9 & S \\
\hline 14- Bacaba & Sequeiro & 2,0 & MS & 1,9 & MS & 1,5 & MS \\
\hline 15- Primavera & Sequeiro & $-2,5$ & S & 2,1 & MS & 1,3 & MS \\
\hline 16- Jaguari & Sequeiro & 3,0 & MT & 3,1 & MT & 4,2 & $\mathrm{~T}$ \\
\hline 17- Bonança & Sequeiro & $-1,5$ & S & 1,5 & MS & 1,5 & MS \\
\hline 18- Firmeza & Irrigado & 8,5 & $\mathrm{~T}$ & 0,5 & S & 1,5 & MS \\
\hline
\end{tabular}

T= Tolerante, $\mathrm{MT}=$ Moderadamente Tolerante, $\mathrm{MS}=$ Moderadamente sensível e $\mathrm{S}=$ sensível ao alumínio.

* Irrigado= genótipos desenvolvidos e cultivados em sistema de irrigação por inundação; sequeiro= genótipos desenvolvidos e cultivados

sem sistema característico de irrigação.

(FURLANI \& FURLANI, 1991), através da expressão: ITR $=\left[\left(C^{2 R R_{X}}-C_{R}\right) /\left(C R R_{T}-C_{S}\right)\right] \times 4+1$. Onde: CRR é o comprimento relativo das raízes e representa a razão entre os valores de comprimento das raízes (CR) de plantas crescidas na presença de alumínio $\left(\mathrm{CR}_{+\mathrm{Al}}\right) \mathrm{e}$ na ausência de alumínio (CR-Al) respectivamente. Os sub-índices $\mathrm{X}, \mathrm{S}$ e $\mathrm{T}$ representam os valores para o material em estudo, testemunha sensível e tolerante, respectivamente. Foram utilizados como controle tolerante o genétipo 2/52/4 (FREITAS, 2003) e sensível BR IRGA 410 (FERREIRA et al., 1995). Desse modo o genótipo com mesmo crescimento de raízes da testemunha tolerante teria ITR $=5$ e o sensível, ITR $=1$ (FURLANI \& FURLANI, 1991), ou seja, $C R R=\mathrm{CR}_{+\mathrm{Al}} /$ $\mathrm{CR}_{\text {-Al }}$. Os genótipos foram classificados com base na seguinte escala: ITR $\geq 4$ tolerante $(\mathrm{T}), 2,6$ à 3,9 moderadamente tolerante (MD), 1,1 à 2,5 moderadamente sensível (MS) e $\leq 1$ sensível (S) ao $\mathrm{Al}^{3+}$ (FURLANI \& FURLANI, 1991).

Os resultados foram submetidos à análise de variância e comparação de médias pelo teste de Scott-Knott para as variáveis mensuradas. Para verificação do efeito dos tratamentos na absorção de nutrientes pelas cultivares testadas, foram estimadas $\mathrm{e}$ representadas as regressões para a absorção de $\mathrm{P}, \mathrm{Mg}$, Ca e K, em função dos níveis de alumínio utilizados.

\section{RESULTADOS E DISCUSSÃO}

A análise de variância (Tabela 2) demonstrou diferenças significativas entre os genótipos para todas as variáveis, evidenciando variabilidade genética na absorção de nutrientes sob estresse causado por alumínio. A interação significativa entre genótipo e alumínio para os nutrientes $\mathrm{P}, \mathrm{Ca}$ e K demonstrou, portanto, diferenças no comportamento dos genótipos ao aumento do nível de alumínio na solução. Foi observado, na análise de regressão (Figura 1), obtida a partir da média dos genótipos, que todos os nutrientes mostraram reduções na absorção com o aumento do alumínio na solução. A redução foi linear na ordem de 0,$16 ; 0,63 ; 0,10$ e $0,2 \mathrm{~g} \mathrm{~kg}^{-1} \mathrm{de} \mathrm{P}, \mathrm{Mg}, \mathrm{Ca}$ e K respectivamente para cada $\mathrm{mg} \mathrm{L}^{-1}$ de alumínio adicionado à solução nutritiva. $\mathrm{O}$ cálcio e o fósforo 
Tabela 2 - Resumo da análise de variância para absorção de fósforo $(\mathrm{P})$, magnésio $(\mathrm{Mg})$, cálcio $(\mathrm{Ca})$ e potássio (K) nas folhas dos 18 genótipos de arroz submetidos a doses crescentes de alumínio em solução nutritiva.

\begin{tabular}{llllll}
\hline & & \multicolumn{5}{c}{ Quadrado Médio } \\
\cline { 2 - 6 } Causas da variação GL & & $\mathrm{P}$ & $\mathrm{Mg}$ & $\mathrm{Ca}$ & $\mathrm{K}$ \\
\cline { 2 - 6 } & 2 & 3,560 & 1,140 & 0,370 & 40,950 \\
Bloco & 3 & $250,290 *$ & $39,670 *$ & $94,600 *$ & $395,630^{*}$ \\
Alumínio (Al) & 6 & 2,590 & 0,400 & 0,440 & 9,478 \\
Residuo (a) & 17 & $30,590 *$ & $2,440 *$ & $3,520 *$ & $59,510^{*}$ \\
Genótipo (G) & 51 & $4,650 *$ & 0,320 & $1,460 *$ & $13,770 *$ \\
Interação (Al x G) & 136 & 1,020 & 0,418 & 0,159 & 7,350 \\
Residuo (b) & 215 & & & & \\
Total & & & & & \\
\hline
\end{tabular}

* Significativo ao nível de $5 \%$ de probabilidade de erro pelo teste F.

foram os nutrientes mais afetados pelo alumínio, apresentando as maiores reduções de absorção (Figura 1). Esses resultados corroboram com as afirmações de FOY (1974), segundo o qual o excesso de alumínio, além de inibir a formação normal da raiz, interfere nas reações enzimáticas e na absorção, transporte e uso de nutrientes pelas plantas. SALVADOR et al. (2000), constataram que doses crescentes de alumínio reduziram a absorção e o transporte de $\mathrm{P}, \mathrm{Ca}, \mathrm{Mg}, \mathrm{S}, \mathrm{Fe}$ e Mn para a parte aérea, sugerindo que a redução de $\mathrm{Ca}$ e Mg deve-se a uma inibição interiônica desses cátions pelo alumínio.

$\mathrm{Na}$ avaliação dos genótipos quanto a tolerância ao alumínio (Tabela 2) pode ser verificado que no nível de $10 \mathrm{mg} \mathrm{L}^{-1}$ os índices de tolerância relativa (ITR) variaram de $-2,5$ a 8,5, extrapolando a escala proposta (1 - 5). Isso aconteceu provavelmente pelo nível dos tratamentos não ser tão estressante e devido alguns genótipos apresentarem desempenho superior ou inferior aqueles utilizados como controle tolerante e sensível, e/ou a diferença genética de crescimento das raízes entre estes dois últimos ter sido muito pequena. O índice de tolerância relativa proposto por FURLANI \& FURLANI (1991) exprime a relação entre o crescimento das raízes na presença e na ausência do $\mathrm{Al}^{3+}$ corrigido para uma escala formalizada para os genótipos testemunha. Este índice vem sendo utilizado em diversos trabalhos de identificação de genótipos tolerantes ao $\mathrm{Al}^{3+}$ (FERREIRA et al.,1995; MISTRO et al., 2001; FREITAS, 2003) ou apresentado sob forma de

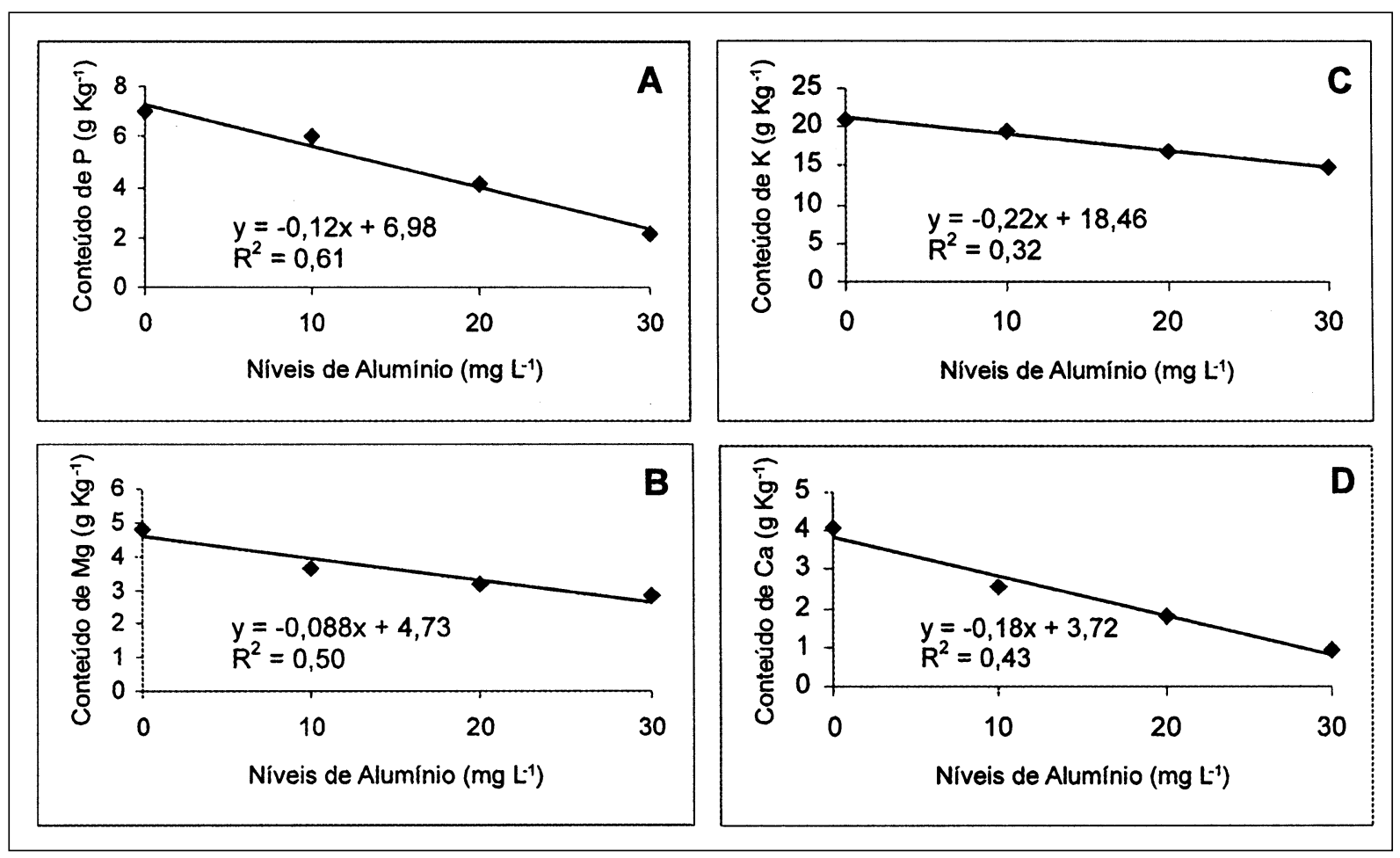

Figura 1 - regressão dos caracteres: (A) conteúdo de fósforo, (B) magnésio, (C) potássio e (D) cálcio em 18 genótipos de arroz submetidos a quatro níveis de alumínio.

Ciência Rural, v.36, n.1, jan-fev, 2006. 
percentagem (FAGERIA \& ZIMMERMANN, 1979; CAMARGO \& OLIVEIRA, 1981; CAMARGO et al., 1998; VASCONCELOS et al., 2002).

O genótipo de arroz Felune foi o único que apresentou índices de tolerância próximos ao controle (2/52/4) em todos os níveis, mostrando-se importante na busca de genótipos com capacidade de adaptação a solos com elevados teores de $\mathrm{Al}^{3+}$. Os genótipos Jaguari e IAC 1246 apresentaram bons índices de tolerância relativa nos níveis mais elevados, sugerindo que sejam utilizados em estudos subseqüentes para a tolerância ao $\mathrm{Al}^{3+}$. O genótipo Taim foi o único sensível em todos os níveis de alumínio, juntamente com o controle BR IRGA 410, indicando ser pouco promissor quanto à tolerância ao alumínio, porém com interesse em estudos genéticos do caráter.

Os genótipos que apresentaram maiores índices de tolerância relativa, na maioria, pertencem ao grupo de sistema de cultivo de sequeiro (Tabela 2). Isso pode ser explicado pelo fato destes genótipos terem sido selecionados indiretamente para este caráter, uma vez que não ocorrem problemas por toxidez por $\mathrm{Al}^{3+} \mathrm{em}$ solos submetidos à irrigação por inundação devido a elevação natural do $\mathrm{pH}$. Desta forma, os genótipos que sofreram o processo de melhoramento em condições de solo arejado, que podem apresentar problemas de toxidez por $\mathrm{Al}^{3+}$, teriam maior freqüência de genes responsáveis pela tolerância. Entre os relatos sobre os mecanismos envolvidos na tolerância ao alumínio, HOWELER \& CADAVID (1976) verificaram que as plantas mais tolerantes apresentaram teores mais elevados de P, Ca, Mg e K. Entretanto, FURLANI \& FURLANI (1991), destacam que o maior teor de nutrientes verificado nas plantas tolerantes ao $\mathrm{Al}^{3+}$ pode ser devido ao efeito indireto do maior aprofundamento e crescimento das raízes, explorando maior volume de solo.

Na tabela 3 pode ser verificado que alguns genótipos absorveram mais fósforo e potássio no nível de $10 \mathrm{mg} \mathrm{L}^{-1}$ de alumínio em relação à solução sem $\mathrm{Al}^{3+}$. Respostas semelhantes foram descritas por FERNANDES \& ROSSIELLO (1995) e VICENTE et al. (1998), que sugerem que este acréscimo de absorção pode ser devido a alguns genótipos aproveitarem beneficamente pequenas concentrações de $\mathrm{Al}^{3+}$ na translocação de $\mathrm{P}$ aumentando assim sua absorção. As cultivares diferiram largamente quanto à absorção de nutrientes (Tabela 3); contudo, percebe-se que para todos os nutrientes houve reduções com o aumento da concentração de alumínio.
O tratamento mais elevado e que distribuiu os genótipos em maior número de classes quanto à absorção de fósforo no teste de comparação de médias (Tabela 3) foi de 30 $\mathrm{mg} \mathrm{L}^{-1}$ totalizando 4 classes (a, b, c e d). Para teor de magnésio, o tratamento foi de $10 \mathrm{mg} \mathrm{L}^{-1}$ com três classes e para cálcio e potássio $30 \mathrm{mg} \mathrm{L}^{-1} \mathrm{com}$ quatro classes para cada nutriente (Tabela 3). O tratamento mais elevado e que distribui os genótipos avaliados em um maior número de classes é indicado para estudos de variabilidade (FERREIRA et al., 1997), sendo muito utilizado em metodologias multivariadas. Assim, fica constatado que cada nutriente estudado possui um nível de tratamento que proporciona melhor discriminação da variabilidade entre os genótipos testados.

Entre os genótipos classificados como tolerantes, nenhum mostrou superioridade na absorção de todos os nutrientes, entretanto os genótipos 2/52/4 e Felune apresentaram comportamento satisfatório para absorção de $\mathrm{P}$ e Ca quando submetidos a doses crescentes de alumínio. O genótipo Felune apresentou ainda o melhor índice de absorção de Ca no nível de $30 \mathrm{mg} \mathrm{L}^{-1}$ de alumínio, sugerindo ser um genótipo com características fisiológicas superiores para a tolerância ao alumínio. Há indícios de que a toxidez por alumínio em plantas esteja ligada ao bloqueio de canais de cálcio na membrana plasmática (JONES et al., 1998). Portanto, diferenças na sensibilidade do sistema de transporte $\mathrm{e}$ absorção de Ca na presença de alumínio sugerem a presença de diferenças genotípicas no funcionamento de canais de Ca (KOCHIAN, 1995), o que pode ser um dos mecanismos responsáveis pela tolerância em arroz.

A análise de correlação de Pearson (Tabela 4) apresenta associações entre todas as variáveis medidas. O comprimento máximo das raízes, obtidos para avaliar a tolerância dos genótipos ao alumínio, expressou coeficientes de correlação significativos com todos os nutrientes. Isso sugere que é possível selecionar plantas de arroz tolerantes ao alumínio com maior absorção de $\mathrm{P}, \mathrm{Mg}, \mathrm{Ca}$ e $\mathrm{K}$ indiretamente pelo desenvolvimento de raízes.

A presença de alumínio debilitou e reduziu o crescimento das raízes, interferindo na absorção de nutrientes. Isso conseqüentemente terá reflexos negativos para o desenvolvimento e produtividade de plantas sensíveis a este elemento. Portanto, constituições genéticas superiores e com capacidade de adaptação a condições nutricionais adversas, especialmente $\mathrm{Pe} \mathrm{Ca}$, poderão amenizar os problemas de baixa produtividade em solos ácidos ocasionado pelo estresse de alumínio. 
Tabela 3 - Concentração de fósforo, magnésio, cálcio e potássio $\left(\mathrm{g} \mathrm{kg}^{-1}\right)$ na matéria seca da parte aérea dos 18 genótipos de arroz cultivados nos níveis de $0,10,20$ e $30 \mathrm{mg} \mathrm{L}^{-1}$ de alumínio.

\begin{tabular}{|c|c|c|c|c|c|c|c|c|c|c|c|c|c|c|c|c|}
\hline \multirow{3}{*}{$\begin{array}{l}\text { Genótipo } \\
\text { 1- Taim }\end{array}$} & \multicolumn{8}{|c|}{ Fósforo } & \multicolumn{8}{|c|}{ Magnésio } \\
\hline & \multicolumn{2}{|c|}{0} & \multicolumn{2}{|c|}{10} & \multicolumn{2}{|c|}{20} & \multicolumn{2}{|c|}{30} & \multicolumn{2}{|c|}{0} & \multicolumn{2}{|c|}{10} & \multicolumn{2}{|c|}{20} & \multicolumn{2}{|c|}{30} \\
\hline & 3,7 & $\mathrm{c}$ & 5,1 & c & 2,9 & c & 0,9 & $\mathrm{~d}$ & 4,4 & $\mathrm{a}$ & 3,1 & $\mathrm{c}$ & 2,7 & b & 2,5 & b \\
\hline 2- L 144 & 4,6 & $\mathrm{c}$ & 3,9 & $\mathrm{~d}$ & 3,4 & $\mathrm{c}$ & 1,4 & d & 5,4 & $\mathrm{a}$ & 4,4 & b & 3,7 & $\mathrm{a}$ & 3,4 & $\mathrm{a}$ \\
\hline 3-Chui & 5,2 & $\mathrm{c}$ & 7,0 & $\mathrm{~b}$ & 1,7 & d & 1,2 & d & 5,8 & a & 5,5 & a & 4,2 & a & 3,9 & $\mathrm{a}$ \\
\hline 4- $2 / 52 / 4$ & 6,3 & $\mathrm{~b}$ & 6,0 & $\mathrm{c}$ & 5,4 & $\mathrm{~b}$ & 4,5 & $\mathrm{a}$ & 5,1 & $\mathrm{a}$ & 3,5 & $\mathrm{c}$ & 3,3 & $\mathrm{a}$ & 2,9 & a \\
\hline 5- BR IRGA 417 & 5,9 & c & 4,5 & $\mathrm{c}$ & 3,2 & c & 2,2 & $\mathrm{c}$ & 4,5 & $\mathrm{a}$ & 3,4 & $\mathrm{c}$ & 3,0 & $\mathrm{~b}$ & 2,5 & b \\
\hline 6- Felune & 7,1 & $\mathrm{~b}$ & 7,5 & $\mathrm{~b}$ & 5,3 & $\mathrm{~b}$ & 3,3 & $\mathrm{~b}$ & 4,4 & $\mathrm{a}$ & 2,8 & $\mathrm{c}$ & 2,5 & $\mathrm{~b}$ & 2,2 & b \\
\hline 7- BR IRGA 410 & 8,4 & $\mathrm{a}$ & 5,8 & $\mathrm{c}$ & 4,2 & $\mathrm{c}$ & 0,6 & $\mathrm{~d}$ & 4,7 & $\mathrm{a}$ & 3,1 & $\mathrm{c}$ & 3,3 & $\mathrm{a}$ & 3,3 & a \\
\hline 8- Epagri 111 & 5,4 & $\mathrm{c}$ & 3,6 & d & 1,0 & d & 0,6 & $\mathrm{~d}$ & 4,5 & $\mathrm{a}$ & 3,8 & $\mathrm{c}$ & 3,4 & $\mathrm{a}$ & 3,0 & $\mathrm{a}$ \\
\hline 9- Supremo 1 & 5,1 & $\mathrm{c}$ & 2,2 & $\mathrm{~d}$ & 1,5 & $\mathrm{~d}$ & 1,3 & $\mathrm{~d}$ & 4,4 & $\mathrm{a}$ & 3,5 & $\mathrm{c}$ & 3,0 & $\mathrm{~b}$ & 2,9 & $\mathrm{a}$ \\
\hline 10-Zebú Branco & 9,3 & a & 7,7 & $\mathrm{~b}$ & 6,3 & $\mathrm{~b}$ & 4,8 & $\mathrm{a}$ & 4,2 & a & 3,6 & $\mathrm{c}$ & 3,4 & $\mathrm{a}$ & 2,4 & $\mathrm{~b}$ \\
\hline 11- Matsuyama & 5,5 & $\mathrm{c}$ & 5,0 & $\mathrm{c}$ & 3,3 & $\mathrm{c}$ & 1,8 & $\mathrm{c}$ & 4,6 & $\mathrm{a}$ & 4,5 & $\mathrm{~b}$ & 3,6 & $\mathrm{a}$ & 2,9 & $\mathrm{a}$ \\
\hline 12- IAC 1246 & 5,5 & c & 5,6 & $\mathrm{c}$ & 4,0 & $\mathrm{c}$ & 3,1 & $\mathrm{~b}$ & 4,7 & $\mathrm{a}$ & 3,5 & $\mathrm{c}$ & 3,0 & $\mathrm{~b}$ & 3,1 & a \\
\hline 13- Toukyo H, & 7,0 & $\mathrm{~b}$ & 5,5 & $\mathrm{c}$ & 0,6 & $\mathrm{~d}$ & 0,6 & $\mathrm{~d}$ & 5,0 & $\mathrm{a}$ & 3,9 & $\mathrm{c}$ & 3,0 & $\mathrm{~b}$ & 3,3 & $\mathrm{a}$ \\
\hline 14- Bacaba & 9,9 & $\mathrm{a}$ & 9,5 & $\mathrm{a}$ & 5,1 & $\mathrm{~b}$ & 0,9 & $\mathrm{~d}$ & 3,9 & $\mathrm{a}$ & 3,0 & $\mathrm{c}$ & 2,6 & $\mathrm{~b}$ & 2,6 & $\mathrm{~b}$ \\
\hline 15- Primavera & 9,7 & $\mathrm{a}$ & 10,1 & $\mathrm{a}$ & 8,7 & $\mathrm{a}$ & 1,3 & d & 4,5 & a & 3,8 & $\mathrm{c}$ & 2,6 & $\mathrm{~b}$ & 2,2 & $\mathrm{~b}$ \\
\hline 16- Jaguari & 7,3 & $\mathrm{~b}$ & 5,2 & c & 3,9 & $\mathrm{c}$ & 2,1 & $\mathrm{c}$ & 4,9 & $\mathrm{a}$ & 3,9 & $\mathrm{c}$ & 3,5 & $\mathrm{a}$ & 2,5 & b \\
\hline 17- Bonança & 9,9 & $\mathrm{a}$ & 7,0 & $\mathrm{~b}$ & 6,0 & $\mathrm{~b}$ & 4,5 & a & 6,0 & $\mathrm{a}$ & 3,5 & $\mathrm{c}$ & 3,4 & $\mathrm{a}$ & 3,0 & a \\
\hline 18- Firmeza & 10,0 & $\mathrm{a}$ & 7,0 & $\mathrm{~b}$ & 5,7 & $\mathrm{~b}$ & 4,6 & $\mathrm{a}$ & 4,8 & $\mathrm{a}$ & 3,4 & $\mathrm{c}$ & 2,6 & $\mathrm{~b}$ & 2,2 & b \\
\hline
\end{tabular}

\begin{tabular}{|c|c|c|c|c|c|c|c|c|c|c|c|c|c|c|c|c|}
\hline \multirow{3}{*}{$\frac{\text { Genótipo }}{1-\text { Taim }}$} & \multicolumn{8}{|c|}{ Cálcio } & \multicolumn{8}{|c|}{ Potássio } \\
\hline & \multicolumn{2}{|c|}{0} & \multicolumn{2}{|c|}{10} & \multicolumn{2}{|c|}{20} & \multicolumn{2}{|c|}{30} & \multicolumn{2}{|c|}{0} & \multicolumn{2}{|c|}{10} & \multicolumn{2}{|c|}{20} & \multicolumn{2}{|c|}{30} \\
\hline & 4,1 & $\mathrm{~b}$ & 2,3 & $\mathrm{c}$ & 2,1 & $\mathrm{~b}$ & 1,1 & $\mathrm{c}$ & 19,9 & $\mathrm{a}$ & 17,2 & $\mathrm{c}$ & 16,5 & $\mathrm{~b}$ & 12,47 & $\mathrm{c}$ \\
\hline 2- L 144 & 6,0 & $\mathrm{a}$ & 2,4 & $\mathrm{c}$ & 1,5 & $\mathrm{c}$ & 1,0 & $\mathrm{c}$ & 20,0 & $\mathrm{a}$ & 21,0 & $\mathrm{~b}$ & 17,2 & $\mathrm{a}$ & 13,60 & $\mathrm{c}$ \\
\hline 3- Chui & 6,5 & $\mathrm{a}$ & 4,0 & $\mathrm{a}$ & 1,9 & b & 1,0 & $\mathrm{c}$ & 18,5 & a & 18,5 & $\mathrm{c}$ & 15,4 & $\mathrm{~b}$ & 15,20 & $\mathrm{c}$ \\
\hline 4- $2 / 52 / 4$ & 5,7 & $\mathrm{a}$ & 3,3 & b & 3,0 & $\mathrm{a}$ & 1,3 & $\mathrm{~b}$ & 18,8 & $\mathrm{a}$ & 16,7 & $\mathrm{c}$ & 14,8 & $\mathrm{~b}$ & 12,89 & $\mathrm{c}$ \\
\hline 5- BR IRGA 417 & 2,7 & $\mathrm{c}$ & 2,1 & $\mathrm{c}$ & 1,4 & $\mathrm{c}$ & 0,8 & $\mathrm{~d}$ & 22,2 & a & 20,3 & b & 16,9 & $\mathrm{~b}$ & 16,66 & $\mathrm{~b}$ \\
\hline 6- Felune & 3,2 & $\mathrm{c}$ & 2,2 & $\mathrm{c}$ & 1,8 & $\mathrm{~b}$ & 1,5 & $\mathrm{a}$ & 23,4 & $\mathrm{a}$ & 17,8 & $\mathrm{c}$ & 18,0 & $\mathrm{a}$ & 16,50 & $\mathrm{~b}$ \\
\hline 7- BR IRGA 410 & 5,4 & $\mathrm{a}$ & 3,7 & $\mathrm{a}$ & 1,4 & $\mathrm{c}$ & 1,2 & $\mathrm{~b}$ & 20,4 & a & 24,0 & $\mathrm{a}$ & 17,8 & $\mathrm{a}$ & 18,51 & $\mathrm{a}$ \\
\hline 8- Epagri 111 & 2,7 & c & 2,6 & c & 2,3 & b & 1,2 & $\mathrm{~b}$ & 25,0 & $\mathrm{a}$ & 21,2 & b & 20,3 & $\mathrm{a}$ & 19,70 & $\mathrm{a}$ \\
\hline 9- Supremo 1 & 2,9 & $\mathrm{c}$ & 1,9 & $\mathrm{~d}$ & 2,1 & b & 0,7 & $\mathrm{~d}$ & 22,8 & $\mathrm{a}$ & 14,8 & $\mathrm{c}$ & 10,3 & $\mathrm{~b}$ & 7,45 & $\mathrm{e}$ \\
\hline 10-Zebú Branco & 3,0 & $\mathrm{c}$ & 1,9 & d & 1,9 & $\mathrm{~b}$ & 1,1 & $\mathrm{c}$ & 21,1 & a & 16,9 & $\mathrm{c}$ & 15,4 & $\mathrm{~b}$ & 13,81 & $\mathrm{c}$ \\
\hline 11- Matsuyama & 2,8 & c & 3,0 & b & 2,3 & $\mathrm{~b}$ & 0,6 & d & 18,1 & a & 18,1 & $\mathrm{c}$ & 16,4 & b & 13,50 & $\mathrm{c}$ \\
\hline 12- IAC 1246 & 4,4 & $\mathrm{~b}$ & 2,7 & $\mathrm{c}$ & 2,3 & b & 1,2 & $\mathrm{~b}$ & 23,8 & a & 25,8 & $\mathrm{a}$ & 20,9 & $\mathrm{a}$ & 19,89 & a \\
\hline 13- Toukyo H, & 4,2 & b & 2,5 & c & 1,3 & $\mathrm{c}$ & 0,8 & $\mathrm{~d}$ & 18,3 & $\mathrm{a}$ & 14,9 & $\mathrm{c}$ & 14,1 & b & 17,35 & $\mathrm{~b}$ \\
\hline 14- Bacaba & 2,6 & $\mathrm{c}$ & 1,4 & $\mathrm{~d}$ & 1,0 & $\mathrm{c}$ & 0,6 & $\mathrm{~d}$ & 21,5 & a & 20,8 & b & 19,5 & $\mathrm{a}$ & 10,24 & d \\
\hline 15- Primavera & 2,8 & c & 2,5 & $\mathrm{c}$ & 2,3 & b & 0,7 & $\mathrm{~d}$ & 17,1 & a & 17,8 & c & 14,4 & $\mathrm{~b}$ & 13,60 & $\mathrm{c}$ \\
\hline 16- Jaguari & 5,4 & $\mathrm{a}$ & 3,9 & $\mathrm{a}$ & 2,4 & b & 0,9 & $\mathrm{c}$ & 20,4 & $\mathrm{a}$ & 20,8 & b & 20,4 & $\mathrm{a}$ & 17,43 & $\mathrm{~b}$ \\
\hline 17- Bonança & 4,3 & b & 2,2 & $\mathrm{c}$ & 1,3 & $\mathrm{c}$ & 1,0 & $\mathrm{c}$ & 25,0 & a & 18,9 & $\mathrm{c}$ & 18,9 & $\mathrm{a}$ & 14,78 & c \\
\hline 18- Firmeza & 4,3 & $\mathrm{~b}$ & 2,6 & $\mathrm{c}$ & 1,1 & $\mathrm{c}$ & 0,7 & $\mathrm{~d}$ & 19,5 & $\mathrm{a}$ & 25,3 & $\mathrm{a}$ & 15,7 & $\mathrm{~b}$ & 13,17 & $\mathrm{c}$ \\
\hline
\end{tabular}

Médias seguidas pela mesma letra na coluna não diferem pelo Teste de Comparação de Médias de Scott-Knott, NS $5 \%$. 
Tabela 4 - Coeficientes de correlação de Pearson entre as variáveis comprimento radicular (CR), absorção de fósforo $(\mathrm{P})$, potássio $(\mathrm{K})$, cálcio $(\mathrm{Ca})$, e magnésio em 18 genótipos de arroz submetidos a níveis crescentes de alumínio.

\begin{tabular}{lllllll}
\hline Variáveis & $\mathrm{n}$ & $\mathrm{CR}$ & $\mathrm{P}$ & $\mathrm{Mg}$ & $\mathrm{Ca}$ & $\mathrm{K}$ \\
\hline $\mathrm{CR}$ & 216 & - & $0,42^{*}$ & $0,55^{*}$ & $0,66^{*}$ & $0,50^{*}$ \\
$\mathrm{P}$ & 216 & & - & $0,38^{*}$ & $0,46^{*}$ & $0,37^{*}$ \\
$\mathrm{Mg}$ & 216 & & & - & $0,7^{*}$ & $0,37^{*}$ \\
$\mathrm{Ca}$ & 216 & & & & - & $0,41^{*}$ \\
$\mathrm{~K}$ & 216 & & & & & - \\
\hline
\end{tabular}

*Significativo a 5\% de Probabilidade pelo teste t.

\section{CONCLUSÕES}

O alumínio tóxico $\left(\mathrm{Al}^{3+}\right)$ nos níveis de 10,20 e 30 $\mathrm{m} \mathrm{L}^{-1}$ reduziu significativamente a absorção de fósforo, magnésio cálcio e potássio nos genótipos de arroz avaliados. O genótipo Felune obteve o melhor desempenho quanto a tolerância ao $\mathrm{Al}^{3+}$ segundo avaliação do crescimento radicular e teores de nutrientes, em particular $\mathrm{P}$ e Ca, juntamente com o controle tolerante 2/52/4. O genótipo Taim foi o mais sensível ao $\mathrm{Al}^{3+}$, apresentando comportamento semelhante ao controle sensível (BR IRGA 410). Correlações significativas foram constatadas entre a absorção de fósforo, magnésio, cálcio e potássio e o desenvolvimento do sistema de raízes nos genótipos estudados quando submetidas a níveis crescentes de $\mathrm{Al}^{3+}$.

\section{REFERÊNCIAS}

BRONDANI, C.; PAIVA, E. Análise de RFLP da tolerância à toxidez do alumínio no cromossomo 2 do milho. Pesquisa Agropecuária Brasileira, Brasília, v.31, n.8, p.575-579, 1996.

CAMARGO, C.E.O. Melhoramento de trigo I. Hereditariedade da tolerância à toxicidade do alumínio. Bragantia, Campinas, v.40, n.4, p.33-45, 1981.

CAMARGO, C.E. O. et al. Avaliação de genótipos de centeio, triticale e trigo comum e trigo duro quanto à tolerância ao alumínio em solução nutritiva. Scientia Agricola, Piracicaba, v.55, n.2, p.227-232, 1998.

CAMARGO, C.E.O.; OLIVEIRA, O.F. Tolerância de cultivares de trigo a diferentes níveis de alumínio em solução nutritiva e no solo. Bragantia, Campinas, v.40, n.3, p.21-31, 1981.

DUNCAN, R.R.; BALIGAR, V.C. Genetics, breeding, and physiological mechanisms of nutrient uptake and use efficiency: an overview. In: BALIGAR, V.C.; DUNCAN, R.R. Crops as enhancers of nutrient use. San Diego: Academic, 1990. Cap.1, p.3-35.

FAGERIA, N.K.; ZIMMERMANN, F.J.P. Seleção de cultivares de arroz para tolerância a toxidez de alumínio em solução nutritiva. Pesquisa Agropecuária Brasileira, Brasília, v.14, n.2, p.141-147, 1979.

FERNANDES, M.S.; ROSSIELLO, O.P.R. Mineral nitrogen in plant physiology and plant nutrition. Critical Reviews in Plant Sciences, Boca Raton, v.14, p.111-148, 1995.

FERREIRA, R.P. et al. Tolerância de genótipos de arroz ao ferro em solução nutritiva. Pesquisa Agropecuária Brasileira, Brasília, v.32, n.11, p.1177-1182, 1997.

FERREIRA, R.P. et al. Identificação de cultivares de arroz tolerantes à toxidez de alumínio por técnica multivariada. Pesquisa Agropecuária Brasileira, Brasília, v.30, n.6, p.789-795, 1995.

FOY, C.D. Effects of aluminum on plant growth. In: CARSON, E.W. (Ed.). The plant root and its environment. Charlottesville: Univ. of Virginia, 1974. p.601-642.

FOY, C.D. et al. Differential aluminum tolerance of two varieties associated with plant-induced $\mathrm{pH}$ changes around their roots. Soil Science Society Proceedings, Beltsville, v.29, n.1, p.64-67, 1965.

FREITAS, F.A. Dissimilaridade genética em arroz (Oryza sativa L.) quanto a toxicidade ao alumínio. 2003. $69 \mathrm{f}$. Dissertação (Mestrado em Ciência e Tecnologia de Sementes) Pós graduação em, Ciência e Tecnologia de Sementes, Universidade Federal de Pelotas.

FURLANI, P.R.; FURLANI, A.M.C. Tolerância a alumínio e eficiência a fósforo em milho e arroz: características independentes. Bragantia, Campinas, v.50, n.2, p.331-340, 1991.

HOWELER, R.H.; CADAVID, L.F. Screening of rice cultivars for tolerance to Al-toxicity in nutrient solution as compared with a field screening method. Agronomy Journal, Madison, v.68, n.5, p.551-555, 1976.

JO, J. et al. Isolation of ALU1-P gene encoding a protein with aluminum tolerance activity from arthrobacter viscosus. Biochemical and Biophysical Research Communications, Korea, v.239, n.3, p.835-839, 1997.

JONES, D.L. et al. Aluminum induces a decrease in cytosolic calcium concentration in BY-2 tabaco cell cultures. Plant Physiology, Rockville, v.116, n.1, p.81-89, 1998.

KOCHIAN, L.V. Cellular mechanisms of aluminum resistance in plants. Annual Review of Plant Physiology, Palo Alto, v.46, p.237-260, 1995.

MISTRO, J.C. et.al. Avaliação de genótipos de trigo, de diferentes origens, em relação à toxicidade de alumínio. Bragantia, Campinas, v.60, n.3, p.177-184, 2001.

OLMOS, I.R.; CAMARGO, M.N. Ocorrência de alumínio tóxico nos solos do Brasil, sua caracterização e distribuição. Ciência e Cultura, Rio de Janeiro, v.28, n.2, p.171-180, 1976. 
PELLET, D.M. et al. Organic acid exudation as an aluminum tolerance mechanism in maize. Planta, New York, v.196, n.4, p.788-795, 1995 .

RYAN, P.R. et al. Characterization of Al-stimulated efflux of malate from the apices of Al-tolerant wheat roots. Planta, New York, v.74, n.1, p.103-110, 1995.

SALVADOR, J.O. et al. Influência do alumínio no crescimento e na acumulação de nutrientes em mudas de goiabeira. Revista Brasileira de Ciência do Solo, Campinas, v.24, n.4, p.787796, 2000.

SAWAZAKI, E.; FURLANI, P.R. Genética da tolerância ao alumínio em linhagens de milho cateto. Bragantia, Campinas, v.46, n.2, p.269-278, 1987.

TEDESCO, M.J. et al. Análise de solo, plantas e outros materiais. 2.ed. Porto Alegre: UFRGS, 1995. 147p.
UEXKULL, H.R; MUTER, T. Global extent, development and economic impact of acid soils. In: DATE, R.A. et al. Plant-soil interactions at low $\mathrm{pH}$ : principles and management. Dordrecht, Netherlands: Kluwer Academic, 1995. p.5-19.

VASCONCELOS, S.S. et al. Parâmetros morfológicos para estabelecer tolerância diferencial à toxicidade de alumínio em cultivares de arroz. Pesquisa Agropecuária Brasileira, Brasília, v.37, n.3, p.357-363, 2002.

VICENTE, F.M.P. et al. Características indicativas de sensibilidade ao alumínio em arroz. Pesquisa Agropecuária Brasileira. Brasília, v.33, n.1, p.9-15, 1998.

WRIGHT, R.J. Soil aluminum toxicity and plant growth. Communications in Soil Science and Plant Analysis, New York, v.20, n.15, p.1479-1497, 1989. 